some of our union establishments, afford valuable data with reference to the effect of insufficient food in the generation of cholera, diarrhœa, \&c. The spurred rye is known to give rise to a peculiar form of gangrene; and some form of fever usuaily follows close upon a haryest in which the corn has not been sufficiently ripened. There can be no question, also, that the exhalations arising from too dense a population are among the most active and efficient causes of epidemics, and exert a marked influence in modifying their p ogress. "The mortality from small-pox," says Mr Farr, "was greater in the metropolis than in all the other parts of England; and the rate of increase in the second, third, and fourth periods was 1.50 , the deaths havilig been 506,753 and 1145 . The rate of increase in the first and second periods was 1.97, the deaths were 257 and 560 .

The decline of the epidemic in the metropolis is shown by the following numbers:-

\begin{tabular}{|c|c|c|c|c|}
\hline $\begin{array}{l}\text { 1. Mean quarterly deaths } \\
\text { registered................. } \\
\text { 2. Calculated series......... }\end{array}$ & $\begin{array}{l}1103 \\
1103\end{array}$ & $\begin{array}{l}959 \\
967\end{array}$ & $\begin{array}{l}611 \\
611\end{array}$ & $\begin{array}{l}240 \\
278\end{array}$ \\
\hline
\end{tabular}

The number 1103 , in the upper line, was the mean of the deaths registered in the fourth and fifth periods; 959 was the mean of the deaths in the fifth and sixth periods; the other numbers were obtained in the same manner. The first rate of the calculated series was 1.14, and the other rates were obtained by multiplying 1.14 four times in succession by 1.39 , the constant."

A coniparative series, deduced by the same methods, is subjoined.

“Wales and the Western Counties of England-

1. Mean quarterly deaths

registered

$\begin{array}{llllllll}157 & 813 & 621 & 489 & 304 & 194 & 116 & 81\end{array}$

The first rate was 1.35 ; the constant, 1.023."

With respect to the opinion that epidemic diseases are generated through the agency of minute insects, or other animalcules belonging to the invertebrate tribes, some curious facts have been recorded in connexion with the recent epidemics of cholera and influenza. The observations and researches of Dr. Holland, Professor Elirënberg, Henle of Berlin, Cagnard-Latour, Schwann, and Montaigne, in relation to this subject, are also highly deserving attention. This, however, is not a place to enter upon the discussion, though we may, upon some future occasion, take an opportunity of collecting such facts of this description as are well authenticated, and bring them before our readers in another shape.

\section{SELF-REFORM OF THE CORPORATIONS.}

$W_{E}$ have receired from an influential friend in Bath the following information, on the accuracy of which we believe that implicit confidence may be placed. A species of reform-committee has been appointed at the College of Surgeons. The members of this committee, selected from the council, are the president and vice-president, Sir Benjamin Bıodie, Mr. Stanley, and Mr. Babington. At the recominendution of the reform-committee, and with the sanction of the College of Physicians, and the Apothecaries' Company, the following changes have been proposed, and will, in all probability, be speedily adopted.

A new class of members is to be instituted at the College of Surgeons, to be entitled "Fellows of the College." Members of this class must undergo a second examination, must be of a certain age, and have had no less than six years' hospital practice. These fellows are in future to elect the council of the College from the hospital surgeons and recognized lécturers throughout the kingdom. Some member of the committee has proposed, that all members of ten years' standing (not practising pharmacy) should have a vote. The College of Physicians propose to make the qualification and right to practise (of physicians) the same all over the United Kingdoin. For this purpose ull physicians, at present practising with a diploma of Doctor of Medicine from any British University, and being 26 years of age, are forthwith to be incorporated with the present College, and become licentiates. In order to do uway with the principle of self-election, the licentiates of the College shall in future propose annually a certain number for election into the fellowship, and from whom the fellows shall elect a certain proportion.

The doctors in medicine of the London University to be admitied licentiates of the College, provided they are 26 years of age. The examinations at the College are to be so regulated, that there shall be but one course of study, and one degree for all its inembers.

The Apothecaries' Company propose to give up the power of searching shops, and to shorten the period of apprenticeship, as they think the system objectionable on its present principles. They abandon the right of prosecuting, \&c., and would prefer "a summary conviction." They also consent to the election of a certain proportion (not exceeding one-half) of the court of examiners, from amongst the licentiates, of ten years' standing. An uniform sum (6l. 6s.) to be paid for the certificate of qualification for town or country.

Acute Hydrocephalus, or Water in the Head, an Inflammatory Disease, and Curable equally and by the same means with other Diseases of Inflammation. By David D. Davis, Professor of Obstetric Medicine in University College, and one of the Physicians to University College Hospital. London: Taylor \& Walton. 1840. 8vo. Pp. 309.

Our attention was first directed to this work by a pompous encomiun of it which appeared in the pages of a contemporary Journal. That "able surgeon and sound lawyer," the Medical Ccoroner for Middlesex, assures us that Dr. Daris's work "will produce a remarkable charige in that department of the healing art to which the subject of it directly refers, and will, in its results, prove equally honourable to medical science and gratifying to the friends of humanity."

We also have carefully perused the treatise of Dr. Davis on acute hydrocephalus, and we regret to say that we have been conipelled to arrive at an exactly opposite cunclusion. Certain circumstances which we shall immediately point out are calculated to render this work the means of reflecting a deep and lasting disgrace on medical literature, to huiniliate all the true friends of science, and to bring more closely home to us the truth of the fact, that " man is, after all, but a miserable mortal." In its conception, this treatise betrays an ignorance of all that has been done ("in that department of the healing art to

- Sic Inquilur Mr. Wakley's Seeretary, Lancet, Dec. 12, p. 399. Alas. Sic Inquilur Mr. Wakley's secretary, Lancet, Dec. 12, p. 399. Alas.
that tlie wortliy coroner should be compelled to blow bis own trumpet at tuch a rate as this! 
which the subject of it directly refers") for the last twentyfive years; in its execution, this treatise is a literary imposture. We regret deeply that we are forced to speak in such harsh terms of one who has hitherto enjoyed a respectable literary rank in the medical world, and who has been connected for so many years, as a teacher, with one of our first medical schools; but the extraordinary effrontery with which Dr. Davis has endeavoured to palm upon the public another man's offspring as his own, merits the exposure which his partially-successful attempt shall now, incontinently, receive.

So grave an accusation as the one we have just made, requires to be sustained by the most clear and convincing proofs; but first, a few words on Dr. Davis's object-on the spirit in which the present treatise has been conceived. "My principal object," says Dr. Davis, " is to impress the profession with the fact, that acute hydrocephalus is not an ordinary dropsy, but the result of an acute inflammatory disease of the vascular tissues of the encephalon. A notion of this kind somewhat doubtfully exists amongst some members of the profession. But the impression in question does not amount to a living practical faith in this country; if, indeed, we may venture to presume that it even approximates to a general opinion."

In the above sentence, we repeat, Dr. Davis shows that he is completely ignorant of the progress of medicine (as far as it regards hydrocephalus) during the last twentyfive years. The last work on hydrocephalus, Dr. Davis informs us, is that of Dr. Gölis, of Vienna. Now this work was published in the year 1815; and we ask any one who has bestowed the slightest attention on diseases of children, whether at least a dozen works have not been written since that period, in all of which the inflammatory nature of hydrocephalus is pointed out; we ask if any English physician, who has been educated within the last twenty years, was ever taught any other doctrine. The inflammatory nature of hydrocephalus has become a household creed; " out of the mouths of babes and sucklings" may the Professor of University College be confuted.

The editors of "Manuals for the Hall,"-the authors of popular treatises on medicine -lay stress upon this doctrine which the worthy Coroner for Middlesex eulogizes as novel. There isn't a farrier in Finsbury but could have taught him better.

This, however, is but a matter of insignificant import, when compared with the second charge which we make with regret against Dr. Davis. Every syllable of his treatise (save the portion devoted to "treatment," and a few remarks on the proximate cause of hydrocephalus) is $a$ literal translation of the treatise of Dr. Gölis on the same subject. 2nd edit. Vienna, 1820.

Dr. Davis's treatise consists of two parts; in the first part we have nine chapters.

Chapter I.- "On the phenomena of the formative stage of hydrocephalus." Every line of this is taken verbatim from Gölis." $†$ Dr. Imray, in the "Cyclopsedia of Popular Medicine," says, "Acute
hydrocephalus consists in an infammation of the membranes which surround the brain, or line its central cavities ;" and again, "We cannot impress too strongly on the minds of parents a knowledge of the fact, that acute dropsy of the brain is really an infammatory disease, and that our only hope of curing it depends on the early and prompt use of active measures."-Dr. Graham, Dr. Macauley, Mr. Meade, and Dr. Steggall, measures."-Dr. Graham, Dr. Macauley, Mr. Meade, and Dr. Steg in nearly as decided terms of the nature of the complaint.

speak in nearly as decided terms of the nature of the complaint.
+ Dr. Juhnson, in noticing this part of Dr. Davis's treatise, says " that it presents a very vivid and faithful picture of the disease." The learned reviewer little dreamed that when quoting Dr. Davis, he was morely citing the text of Gölis. No wonder that the picture was vivid end failhful.

Chapter II._- Of the second, or inflammatory period, of acute hydrocephalus." Every line of this chapter is taken, in a similar way, from Gölis. We give an example lower down.

Chapter III.- "Of the third stage of acute hydrocephalus, or of the period of effusion and palsy." Ciolis verbatim.t Dr. Davis acknowledges to have burrouped this chapter or section.

Craptra IV. - " Of the diagnosis of acute hydrocephalus." Stolen, every word, without acknowledgment, from Gölis, pages 50-4.

Chapter V.- "Pathognomic symptoms of the second stage, or that of inflammation." This section is alsu taken, every line and letter, from Gölis.

Chapter VI.- " Of the pathogomonic symptoms of the third stage." Poor Gölis again, totidem verbis. The only variation is in the heading; last chapter it was " puthognomic," here it is pathognomonic.

The principal part, then, of Dr. Davis's treatise is a literal translation of Gölis's work. The following extracts, taken at random, show upon what grounds we make this assertion; and we pledge our literary reputation, that the other portions which we have indicated, (without translating them,) are equally close transcripts of the text of the German physician.

$$
\text { cörıs. }
$$

The nose is always dry; the once rosy lips are now pale, or of a dull, dark, red culour, and are chapped through their dryness. The tongue, which at first was clean, is now covered with a white or brownish-yellow fur; thirst and hunger, in most cases, cease altogether, but in the tumultuous accession" the former is sometimes for a short time unsatiable, and a few patients ask to eat and drink, or even appear to be very hungry.

The patients commonly vomit four to six times in twenty-four hours; but these vomitings become less frequent as the disease progresses to the following stage, sometimes cease altogether, and are increased by any motion of the patient, or attempt to sit up in bed. The digestive power, which already in the former stage had begun to get weak, is generally altogether lost. The patients frequently pass the food which they had taken several days before, undigested, mixed with a quantity of mucus, and emitting a fetid smell.

t This explains and justifies the following remark of Dr. Forbes, in his reviev of Dr. Davis's work, "The symptoms of the third stage are accurately related, allowance. being made for obscurity and other vices of style, which in this part of the book seem to have attained their highest pitch." which in this part of the book seem to have attain
The nose is always dry; the lips, formerly of a rosy hue, now present the complexion of a faint dark red, and moreover fissured by reason of their dryness; the tongue, which at first was clean, now becomes covered with a white or brownishyellow fur; thirst and appetite for food are easily appeased or entirely cease, excepting in one form of the malady, during the inflammatory stage of the disease, which seizes its victim in a tempest of symptoms called by Gölis "the tumultuous accession of hydrocephalus."

On the contrary, the stomach is often disturbed by nausea and retchings to vomit; the contents of the stomach being rejected four or six times in twenty-four hours. But these vomitings become less and less frequent as the disease advances to its next subsequent stage, or, as sometimes happens, ceases entirely. When it continues, it is principally aggravated on the patient attempting to move or sit up in bed. The power of digestion, which even in the formative stage of the disease had become inuch diminished, commonly ceases
altogether during this stage 
In the tumultnous attack of this disease some patients are constantly chewing or champing. The expired air has, in most cases, at this period a peculiarly fetid odour, which Whytt and Sprengel have already observed, but which Cheyne denies. The regions of the stomach and liver are tender when strongly pressed upon; the abdomen, which in most cuses, at the commencement was very large and tumid, falls in without any purging; and I am disposed to regard this retracted condition of the abdomen as a pathognomic sign of acute hydrocephalus.

The bowels often remain obstinately constipated, notwithstanding purgatives and clysters; Quin, Sprengel, Miller, and almost all writers have remarked this symptom. The stools are slimy und viscid, generally of a brown colour (sometimes yellow-brown) and not very fetid. When calomel has been used, they are green, in all its shades.

Flatulency scarcely ever exists ; Portenschlag regards it as of frequent occurrence; but in such cases the form of disease was the wateratroke (wasserschlag) or there was a complication of some other affection.

The urine, which, according to $\mathrm{my}$ own experience, and that of other physicians, is always scanty, and often voided with pain, is at the beginning turbid, or of a dirty white colour; but in the following stages it is of a deep yellow colour, with a characteristic heavy, slimy deposit. Although the urine remains, at this period of the disease, sometimes turbid, it smells little, but in a few hours it ferments and then affects the olfactory nerves more.

The hearing now becomes fine and acute; loud tones of inflammation. Food taken many days before often passes undigested, unhealthy both as to its appearance and fotor; consisting of much unhealthy-looking mucus, admingled with a great quantity of viscid and vitiated bile.

and noisy sounds strike painfully on the ear. A perpetual moaning, and complaints of pain in the belly, neck, or (more commonly) the head, affect the bystanders in the highest degree. The nights are mostly sleepless, or the sleep is disturbed.

the tumultuous accession of this disease, some patients are constantly ehewing. At length the breath begins to be tainted by a very sickly, offensive odour. Pressure on the pit of the stomach occasions much tenderness. The abdomen, which may be tumid at the beginning of the malady, subsides surprisingly in its progress, even without any increased evacuation from the bowels. The fulling of the abdomen may indeed be considered as one of the pathognomic indications of acute hydrocephalus.

The bowels often remain obstinately constipated, in spite of active purgatives and also of injections. Thestools are gluey, most commonly brown, sometimes of a clay colour, and at other times of a yellowish green. During the use of calomel, green indeed, in allits several shades, is the predominant colour. The motions also are for the most part slimy and fœtid.

Flatusscarcely ever passes, excepting under the most tumultuous forms of the disease; especially in that remarkable varietyofit to which Gölis and other German writers have given the name of wasser schlag, or water stroke, which also is that presumed by Dr. Charles Quin to have been the apoplexia hydrocephalica of Cullen.

The urine is always scanty, and voided with pain. At the beginning it is generally turbid and white; but in the following stages its hue is that of whitish yellow with a heavy slimy deposit. If at this period of the disease this sediment should form, the urine will nevertheless remain turbid, and will affect the smell but slightly; but soon after it rans into the putrid fermentation, and it will then affect the olfactories more sensibly.

The sense of hearing now becomes more acute, and

The poor little patients often grind their teeth, dream much, or scream out during their dreams; they only answer when frequently spoken to, and then in a few words. tremely languid; they sit up with difficulty to drink, or for other purposes, and cannot sustain the sitting posture long without support, or bringing on nausea and vomiting. the slow pulsations we often in some cases, of children under twelve months, who exhibited all the symptoms of this stage, I have found it feverish, though perfectly regular. Should the patient suddenly awake, through a dream or fright, or from pain in the head, the frequency of the pulse becomes time. ease,) and furnishes a very of acite hydrocephalus. loud sounds more painful. A constant moan, with complaints of pain in the stomach and abdomen, at the nape of the neck, and the occipital region of the head, excite in the attendants the most heartfelt anxiety and pity. The nights are for the most part sleepless, or else the sleep is exceedingly disturbed.

Their movements are ex-

The pulse is slow, unequal, and intermitting. Between feel a small, dull stroke. But instantly doubled for a short

This pulse, according to my experience, always accompanies this stage of hydrocephalus, (when not complicated with any other dissure sign of the second stage

On such an unworthy plagiarism we shall not offer a word of comment; the most charitable construction that we can put upon it being, that it is the aberration of an effete intellect.

Chaptex IX. is devoted to the "specially predisposing causes of acute hydrocephalus." Here, for the first time, we met with some original and useful observations on the effects of teething and spoon-diet as predisposing causes of the disease; but the rest of the section is, as usual, taken from Gölis. So is the whole of Section X., in which " the exciting causes of acute hydrocephalus" are described.

Section XI. is devoted to an examination of "the proximate canse of acute hydrocephalus." This section 
contains no less than 110 pages, (more than one-third of the entire work,) into which Dr. Davis has contrived to transfer thirty-seven cases from Gölis, not to mention several observations from the works of Quin and Cheyne. The original work of Gölis contained exactly thirty-seven casès; every one of these has Dr. Ddvis, with unrelentless hand; seized upon and displayed in his pages, for the superfluous purpose of proving to us that hydrocephalus is an inflammatory disease. Well might we exclaim with the puet,

\section{"Non tali auxillo nec defensoribus istis
Tempus egit."}

We have now accompanied Dr. Davis to the last section of his work, in which he describes the means to be employed in the treatment of acute hydrocephalus. The first and main remedy is bleeding, (at the outset of the disease,) carried to full and decided fainting. This sweeping recommendation, which would have startled even Broussais himself, is made without the slightest qualification, or any attempt to point out those cuses in which every practical physician knows that copious blood-letting would be attended with the worst results. But even here Dr. Davis shows himself to be incapable of producing anything original. His formula for blood-letting, which are quoted as original by the Editor of the Lancet, by Dr. Johnson, and by Dr. Forbes, are taken, slightly altered, and without acknowledgment, from Gölis. Thus, Dr. Davis informs us that-

"From a very early age forward to one year old, the quantity of blood to be abstracted should be from 3 to 5 ounces. In cases of two years old, from $5 \frac{1}{2}$ to 6 ounces. In cases of between three and five years old, I usually prescribe the abstraction of between 5 and 10 uunces of blood."

Now what does Gölis say?

"From six months up to one yeat old, 3, 4, or 5 ounces. In cases of children aged two to four years, from 4 to 6 ounces may be taken; and in older children, a still greater quantity may be abstracted, and the bleeding repeated according to circumstances." P. 154.

But enough of this. Our readers are, probably, as tired as ourselves of this exposure. We therefore recommend them to enjoy a little recreation in the perusal of Dr. Davis's cases of acute hydrocephalus cured by blood-letting after his formula. Such cases of hydrocephalus we never saw recorded in any medical work; besides, hundreds of such cases are daily treated and cured without copious blood-letting; yet the well-educated and truly practical physicians under whose care they have prospered, never dreamed of denominating them "hydrocephalus."

In conclusion, we would apply to Dr. Davis the remark which he has applied (Introduction, p. 16,) to Dr. Cheyne, " one wonders what could have induced the author to waste his time in writing such a book on the subject of hydrocephalus," and say to him,

$$
\text { " } \wedge \text { unc vale, si possis." }
$$

\section{ON THE RESUSCITATION OF STILL-BORN CHILDREN.}

By J. TOOGOOD, EsQ. Senior Surgeon to the Bridgewater Infirmary.

CASES of apparently still-boru children are very commen. The attempts to restore life are frequently ili-directed, and not calculated to promote the object. It will be found that a very large proportion of children, apparently dead boru; may be resuscitated, if proper means be resorted to and persevered in for a sufficient length of time; but the modes generally employed to restore life, such as immersing the infant in warm water, friction, and pouring stimulants diown the throat, are not at all calculated to produce the effect initended: and if these means do not succeed atter a short trial, all further attempts are generally abandoned. The plan which.I always, adopt, which has never failed where the cliild was living during birth, is very simple, and only requires persererance. The following cases, under circumstances by no. means favourable, which have been selected from a great many more, will prove the success of the practice recommended.

CAsE I. - Grace White, a very weakly woman, far advanced in consumption, was seized in the morning with uterine hainorrhage, which continued slightly till the evening, when I saw her, and, whilst standing by her bedside, the flooding increased with such violence that I thought it best to deliver her isstantly; the child was still-born. As soon as I had removed it from the mother, and seen her safe from any immediate'danger, I placed a napkin over the child's mouth, and influted its lungs from my own mouth, pressing out the air from the chest afterwards, and thus imitating natural respiration. After having continued this process for thirty-five minutes, the child made a very slight attempt to breathe, and the face became slightly suffused; by persevering ten minutes longer, the free action of the lungs was established, and the child cried lustily.

CASE II.- The next case was that of a poor woman named Sarah Holmes, of the parish of Spaxton, who had been in labour a long time, with a presentation of the arm; and, as it was her firs' confinement, it became very difficult to turn the child, particularly as she was advanced in age, and the parts were very rigid. The child was still-born; but, by pursuing the same plan actively for three quarters of an hour, animation was perfectly restored.

CAPE III.-The next was a case of presentation of the funis, and the labour was slow, the cliild was still-born, but recovered by the same means in half an hour.

Case IV. - The last case which I shall mention was such as to encourage the attempt at resuscitation under any citcumstances; it was a case of twins. The second child presented the head, before which a considerable portion of the funis had descended. The delivery was extremely slow, from the general weakriess of the woman, who had been fur a long time in a bad state of health, and the child was born apparently quite dead. As the mother's situation was very critical, more than half an hour had elapsed before 1 conld aitend to the child, and, on inquiring, 1 found it liad been wrapped in a cloth and placed on a chair in àrotlier roóm. 1 immediately made the attempt to restore it; and, by persevering steadily for twenty-five minutes, I had the satisfaction to see symptoms of returning life; and in about fifteen minutes more the child breathed freely.

\section{REMARRS.}

Every thing in this last case was unfavourable to the restoration of the child; the mother's long-continued disease, the circumstance of her -having two children, and more particularly the delay: which tqok place before any attempt was made, during which time the child was exposed in a rown wilhout Gre in the winter time, with a partial and very slight covering. I am warranted, by my own experience, in recolymending. the attempt to restore all stili-born cliildren wha have been alive during the birth; and if the means of resuscitation, abovementioned be actively employed, and steadly pensevered in, 1 believe the majority of chses will be rucessful. In all cases the restoration of a child is a mogtsatisfactory circumstance, and, in some instances, of the greatest possible consequence. I have never found any thing needsary but the regular inflation of the lungs, which I do with: my own mouth in the way I have described, and have generally observed the firct symptom of returning life to be a tremulous motion of the respiratory organs; the child next makes a feeble attempt to inspire, and the colour of the face changes. 'The 